\title{
Engineering cartilage or endochondral bone: A comparison of different naturally derived hydrogels
}

\author{
Eamon J. Sheehy ${ }^{1,2}$, Tariq Mesallati ${ }^{1,2}$, Tatiana Vinardell ${ }^{3}$, Daniel J. Kelly ${ }^{1,2,4} *$
}

${ }^{1}$ Trinity Centre for Bioengineering, Trinity Biomedical Sciences Institute, Trinity College Dublin, Dublin, Ireland.

${ }^{2}$ Department of Mechanical and Manufacturing Engineering, School of Engineering, Trinity College Dublin, Dublin, Ireland.

${ }^{3}$ School of Agriculture and Food Science, University College Dublin, Belfield, Dublin 4, Ireland.

${ }^{4}$ Advanced Materials and Bioengineering Research Centre (AMBER), Royal College of Surgeons in Ireland and Trinity College Dublin, Dublin, Ireland

\section{*Corresponding author}

E-mail address: kellyd9@tcd.ie

Address: Department of Mechanical and Manufacturing Engineering

School of Engineering

Trinity College Dublin

Dublin 2

Ireland

Telephone: +353-1-896-3947

Fax: +353-1-679-5554 


\section{Abstract}

Cartilaginous tissues engineered using mesenchymal stem cells (MSCs) have been shown to generate bone in vivo by executing an endochondral program. This may hinder the use of MSCs for articular cartilage regeneration, but opens the possibility of using engineered cartilaginous tissues for large bone defect repair. Hydrogels may be an attractive tool in the scaling-up of such tissue engineered grafts for endochondral bone regeneration. In this study, we compared the capacity of different naturally derived hydrogels (alginate, chitosan, and fibrin) to support chondrogenesis and hypertrophy of MSCs in vitro and endochondral ossification in vivo. In vitro, alginate and chitosan constructs accumulated the highest levels of sGAG, with chitosan constructs synthesising the highest levels of collagen. Alginate and fibrin constructs supported the greatest degree of calcium accumulation, though only fibrin constructs calcified homogenously. In vivo, chitosan constructs facilitated neither vascularization nor endochondral ossification, and also retained the greatest amount of sGAG, suggesting it to be a more suitable material for the engineering of articular cartilage. Both alginate and fibrin constructs facilitated vascularization and endochondral bone formation as well as the development of a bone marrow environment. Alginate constructs accumulated significantly more mineral and supported greater bone formation in central regions of the engineered tissue. In conclusion, this study demonstrates the capacity of chitosan hydrogels to promote and better maintain a chondrogenic phenotype in MSCs and highlights the potential of utilizing alginate hydrogels for MSC-based endochondral bone tissue engineering applications.

Keywords: mesenchymal stem cell; hydrogel; alginate; chitosan; fibrin; endochondral ossification. 


\section{Introduction}

Tissue engineering involves using a combination of cells, three-dimensional scaffolds and signaling molecules to repair or regenerate damaged or diseased tissues $[1,2]$. The use of a supporting scaffold or hydrogel facilitates the scaling-up of tissue engineered grafts to clinically relevant sizes. Furthermore, understanding how cell-scaffold interactions regulate the terminal phenotype of the cell is critical in the development novel tissue regeneration strategies. To date, cell-based bone tissue engineering applications have generally focused on the direct osteogenic priming of mesenchymal stem cell (MSC) seeded scaffolds in a process resembling intramembranous ossification [3]. This approach however, has been hampered by insufficient vascularization of the graft following in vivo implantation, thus preventing the necessary delivery of oxygen and nutrients required to ensure cell survival [4]. For example, in vitro osteogenic priming of engineered constructs has been shown to occlude the pores of a scaffold with calcified matrix, resulting in the development of a necrotic core upon implantation into bony defects [5]. Core necrosis is a well-documented challenge in the field of tissue engineering, and will be exacerbated by the scaling-up of such constructs to treat critically sized bone defects.

In an attempt to address these challenges, there has been a recent shift away from classical tissue engineering paradigms, towards strategies aimed at recapitulating the natural mechanisms which drive tissue development during skeletogenesis [6]. The long bones of the body form by a process termed endochondral ossification, whereby chondrocytes in a developing cartilaginous rudiment undergo hypertrophy and direct vascularization and remodeling of the cartilaginous template into bone [7]. An endochondral approach to bone tissue engineering may circumvent many of the issues associated with the intramembranous method, as cells progressing down the endochondral route are equipped to survive hypoxic conditions and release pro-angiogenic factors for the conversion of avascular tissue to 
vascularized tissue [8]. Indeed, it has been demonstrated that MSC-based cartilaginous grafts can be used to generate bone in vivo in both ectopic and orthotopic sites by executing such an endochondral program [8-15].

Hydrogels are water swollen cross linked polymers capable of forming large, abstract shaped constructs [16]. They can be derived from natural materials which are either components of, or have macro-molecular properties similar to, native extra-cellular matrix [17], and a number of naturally derived hydrogels have been shown to support chondrogenesis of MSCs in vitro [18-22]. Previous studies have compared the chondrogenic capabilities of MSC-seeded hydrogels in vitro [23-26], and also the potential of chondrogenically primed MSC-seeded hydrogels to maintain a stable chondrogenic phenotype in vivo [27-29]. However, little is known about the capacity of different MSCseeded hydrogels to support the development of either phenotypically stable cartilage or endochondral bone in vitro and in vivo.

Therefore, the objective of this study was compare the capacity of different naturally derived hydrogels (alginate, chitosan and fibrin) to support chondrogenesis and hypertrophy of MSCs in vitro, and subsequent endochondral ossification in vivo. In the first phase of the study, MSCs were encapsulated in alginate, chitosan, and fibrin hydrogels and cultured in chondrogenic conditions (5 weeks) in order to promote chondrogenesis and cartilaginous matrix production. Thereafter, constructs were switched to hypertrophic conditions (3 weeks) in order to promote a hypertrophic phenotype and the development of calcified cartilaginous tissue. In the second phase of the study MSCs were encapsulated in alginate, chitosan, and fibrin hydrogels and subjected to a shorter in vitro culture period (6 weeks) prior to subcutaneous implantation into nude mice for an additional 6 weeks. 


\section{Materials and methods}

\subsection{Isolation and expansion of MSCs}

Bone marrow derived MSCs were isolated from the femoral shaft of 4 month old pigs and expanded according to a modified method for human MSCs [30] in high glucose Dulbecco's modified eagle's medium GlutaMAX (hgDMEM) supplemented with 10\% v/v foetal bovine serum (FBS), $100 \mathrm{U} / \mathrm{mL}$ penicillin - $100 \mu \mathrm{g} / \mathrm{mL}$ streptomycin (all Gibco, Biosciences, Dublin Ireland) and $2.5 \mu \mathrm{g} / \mathrm{mL}$ amphotericin B (Sigma-Aldrich, Dublin, Ireland) at $20 \% \mathrm{pO}_{2}$. Following colony formation, MSCs were trypsinised, counted, seeded at density of $5 \times 10^{3}$ cells $/ \mathrm{cm}^{2}$ in $500 \mathrm{~cm}^{2}$ triple flasks (Thermo Fisher Scientific), supplemented with hgDMEM, $10 \% \mathrm{v} / \mathrm{v}$ FBS, $100 \mathrm{U} / \mathrm{mL}$ penicillin $-100 \mu \mathrm{g} / \mathrm{mL}$ streptomycin, $2.5 \mu \mathrm{g} / \mathrm{mL}$ amphotericin $\mathrm{B}$, and $5 \mathrm{ng} / \mathrm{mL}$ human fibroblastic growth factor-2 (FGF-2; Prospec-Tany TechnoGene Ltd., Israel) and expanded to passage 2 .

\subsection{Encapsulation of MSCs within alginate, chitosan and fibrin hydrogels}

A $4 \%$ agarose-based mould was used to cast cylindrical ( $\varnothing 5 \times 3 \mathrm{~mm})$ alginate, chitosan and fibrin hydrogels at a cell density of $20 \times 10^{6} \mathrm{MSCs} / \mathrm{mL}$. Alginate constructs were fabricated by injecting passage 2 MSC-laden 2\% w/v alginate (Pronova, FMC Biopolymer, Norway) into a $4 \%$ agarose $/ 50 \mathrm{mM} \mathrm{CaCl} 2$ mould, and allowing gelation to occur for $30 \mathrm{~min}$. Chitosan constructs were fabricated by combining $1.5 \mathrm{~mL}$ of $3 \% \mathrm{w} / \mathrm{v}$ chitosan (Pronova) with $350 \mu \mathrm{L}$ of $\beta$-glycerophosphate ( $\beta$-GP; $600 \mathrm{mg} / \mathrm{mL}$; Sigma-Aldrich, Dublin, Ireland), $360 \mu \mathrm{L}$ of hydroxyethylcellulose (HEC; $25 \mathrm{mg} / \mathrm{mL}$; Sigma-Aldrich) and $790 \mu \mathrm{L}$ of MSC suspension and allowing gelation to occur at $37{ }^{\circ} \mathrm{C}$ for $30 \mathrm{~min}$ to yield a final concentration of $1.5 \% \mathrm{w} / \mathrm{v}$ chitosan, 7\% w/v $\beta$-GP and $0.3 \%$ w/v HEC. Fibrin constructs were fabricated by dissolving $100 \mathrm{mg} / \mathrm{mL}$ bovine fibrinogen (Sigma-Aldrich) in 10,000 KIU/mL aprotinin (Norma Pharma, UK) containing $19 \mathrm{mg} / \mathrm{mL}$ sodium chloride $(\mathrm{NaCl})$. This solution was laden with MSCs and 
combined 1:1 with a $5 \mathrm{U} / \mathrm{mL}$ thrombin in $40 \mathrm{mM} \mathrm{CaCl}_{2}$ solution and allowed to gel at $37^{\circ} \mathrm{C}$ for $30 \mathrm{~min}$ yielding a final concentration of $50 \mathrm{mg} / \mathrm{mL}$ fibrinogen, $2.5 \mathrm{U} / \mathrm{mL}$ thrombin, 5,000 $\mathrm{KIU} / \mathrm{mL}$ aprotinin, $17 \mathrm{mg} / \mathrm{mL} \mathrm{NaCl}$ and $20 \mathrm{mM} \mathrm{CaCl}_{2}$.

\subsection{In vitro culture conditions}

The chondrogenic culture conditions applied in this study are defined as culture in a chondrogenic medium (CM) consisting of hgDMEM GlutaMAX supplemented with 100 $\mathrm{U} / \mathrm{mL}$ penicillin/streptomycin (both Gibco), $100 \mu \mathrm{g} / \mathrm{mL}$ sodium pyruvate, $40 \mu \mathrm{g} / \mathrm{mL} \mathrm{L-}$ proline, $50 \mu \mathrm{g} / \mathrm{mL}$ L-ascorbic acid-2-phosphate, $4.7 \mu \mathrm{g} / \mathrm{mL}$ linoleic acid, $1.5 \mathrm{mg} / \mathrm{mL}$ bovine serum albumine, 1×insulin-transferrin-selenium, $100 \mathrm{nM}$ dexamethasone (all from SigmaAldrich), $2.5 \mu \mathrm{g} / \mathrm{mL}$ amphotericin $\mathrm{B}$, and $10 \mathrm{ng} / \mathrm{mL}$ of human transforming growth factor- $\beta 3$ (TGF- $\beta 3$ ) (Prospec-Tany TechnoGene Ltd., Israel) at 5\% $\mathrm{pO}_{2}$. The hypertrophic culture conditions applied are defined as culture in a hypertrophic medium consisting of high glucose DMEM GlutaMAX supplemented with $100 \mathrm{U} / \mathrm{mL}$ penicillin/streptomycin, 100 $\mu \mathrm{g} / \mathrm{mL}$ sodium pyruvate, $40 \mu \mathrm{g} / \mathrm{mL}$ L-proline, $50 \mu \mathrm{g} / \mathrm{mL}$ L-ascorbic acid-2-phosphate, 4.7 $\mu \mathrm{g} / \mathrm{mL}$ linoleic acid, $1.5 \mathrm{mg} / \mathrm{mL}$ bovine serum albumine, $1 \times$ insulin-transferrin-selenium, 1 $\mathrm{nM}$ dexamethasone, $2.5 \mu \mathrm{g} / \mathrm{mL}$ amphotericin B, $1 \mathrm{nM}$ L-thyroxine (Sigma-Aldrich) and 20 $\mu \mathrm{g} / \mathrm{mL} \beta-\mathrm{GP}$ at $20 \% \mathrm{pO}_{2}$.

\subsection{Experimental design}

The first phase of this study examined the in vitro development of MSC-seeded alginate, chitosan and fibrin cylindrical hydrogels. Constructs were maintained in chondrogenic culture conditions for a period of 5 weeks, and thereafter were switched to hypertrophic culture conditions for an additional 3 weeks. The second phase of the study investigated the capacity of MSC-seeded alginate, chitosan and fibrin hydrogels to undergo endochondral ossification in vivo. Constructs were maintained in chondrogenic culture conditions for a 
period of 5 weeks, followed by an additional week in hypertrophic culture conditions. At the end of the 6 week in vitro culture period a single channel $(\varnothing 2 \mathrm{~mm})$ was cored into the constructs prior to subcutaneous implantation in nude mice for 6 weeks.

\subsection{In vivo subcutaneous implantation}

MSC- seeded alginate, chitosan, and fibrin hydrogels were implanted subcutaneously into the back of nude mice (Balb/c; Harlan, UK) as previously described [31]. Briefly, 2 subcutaneous pockets were made along the central line of the spine, one at the shoulders and the other at the hips, and into each pocket 3 constructs were inserted. 9 constructs were implanted per group and constructs were harvested 6 weeks post-implantation. Mice were sacrificed by $\mathrm{CO}_{2}$ inhalation and the animal protocol was reviewed and approved by the ethics committee of Trinity College Dublin.

\subsection{Biochemical analysis}

The biochemical content of alginate, chitosan and fibrin constructs were analyzed at weeks 5 and 8 of in vitro culture. Prior to biochemical analysis, constructs were sliced in half, washed in PBS, weighed, and frozen for subsequent assessment. One half of each construct was digested with papain $(125 \mu \mathrm{g} / \mathrm{mL})$ in $0.1 \mathrm{M}$ sodium acetate, $5 \mathrm{mM}$ L-cysteine-HCL, $0.05 \mathrm{M}$ ethylenediaminetetraacetic acid (EDTA), pH 6.0 (all from Sigma-Aldrich) at $60{ }^{\circ} \mathrm{C}$ and 10 rpm for $18 \mathrm{~h}$. The amount of sulphated glycosaminoglycan (sGAG) was quantified using the dimethylmethylene blue dye-binding assay (Blyscan, Biocolor Ltd., Northern Ireland), with a chondroitin sulphate standard. Total collagen content was determined by measuring the hydroxyproline content, using a hydroxyproline-to-collagen ratio of 1:7.69. The other half was digested in $1 \mathrm{M}$ hydrochloric acid at $60{ }^{\circ} \mathrm{C}$ and $10 \mathrm{rpm}$ for $18 \mathrm{~h}$. The calcium content was determined using a Sentinel Calcium kit (Alpha Laboratories Ltd, Uk). 3-4 constructs per group were analyzed by each biochemical assay. 


\subsection{Histological and immunohistochemical analysis}

Constructs were fixed in $4 \%$ paraformaldehyde, dehydrated in a graded series of ethanols, embedded in paraffin wax, sectioned at $8 \mu \mathrm{m}$ and affixed to microscope slides. Postimplantation constructs were decalcified in EDTA for up to 1 week. The sections were stained with haematoxylin and eosin $(\mathrm{H} \& \mathrm{E})$ to assess bone formation, $1 \%$ alizarin red to assess calcium accumulation, and aldehyde fuschin/ alcian blue to assess sGAG content. Collagen types I, II and X were evaluated using a standard immunohistochemical technique as described previously [32].

\subsection{Micro-computed tomography}

Micro-computed tomography scans were performed on constructs using a Scanco Medical 40 $\mu \mathrm{CT}$ system (Scanco Medical, Bassersdorf, Switzerland). Constructs were scanned in PBS, at a voltage of $70 \mathrm{kVp}$, and a current of $114 \mu \mathrm{A}$. A Gaussian filter (sigma=0.8, support=1) was used to suppress noise and a global threshold corresponding to a density of $399.5 \mathrm{mg}$ hydroxyapatite $/ \mathrm{cm}^{3}$ was applied. 3D evaluation was carried out on the segmented images to determine bone volume and density and to reconstruct a 3D image. The variance of mineralization with depth through cylindrical constructs was analyzed qualitatively by examining sections corresponding to a thickness of $96 \mu \mathrm{m}$ at a depth of $25 \%$ from the top of the construct (quarter section), and a depth of 50\% from the top of the construct (center section). 4 constructs were analyzed per group.

\subsection{Statistical analysis}

All statistical analyzes were carried out using Minitab 15.1. Results are reported as mean \pm standard deviation. Groups were analyzed by a general linear model for analysis of variance with groups of factors. Tukey's test was used to compare conditions. Anderson-Darling 
normality tests were conducted on residuals to confirm a normal distribution. Non-normal data was transformed using the Box-Cox procedure. Significance was accepted at a level of $p$ $<0.05$. 


\section{Results}

3.1. The in vitro development of hypertrophic cartilaginous grafts engineered using MSCseeded alginate, chitosan and fibrin hydrogels.

\subsubsection{Biochemical analysis}

MSCs were encapsulated in alginate, chitesan, and fibrin hydrogels, and maintained in chondrogenic culture conditions for a period of 5 weeks, followed by an additional 3 weeks in hypertrophic culture conditions. After 5 weeks of chondrogenic culture, sGAG accumulation was significantly higher within MSC-seeded alginate hydrogels $(1.29 \pm 0.07$ $\mathrm{mg})$ compared to chitosan $(\mathrm{p}=0.0451)$ and fibrin $(\mathrm{p}<0.0001)$ hydrogels, see Figure 1a. During this period, collagen synthesis was significantly higher in chitosan constructs $(620 \pm 32 \mu \mathrm{g}$, $\mathrm{p}<0.05)$, and collagen synthesis continued to increase in both chitosan and fibrin constructs during the hypertrophic culture period (Figure 1b). Calcium accumulation also increased during the hypertrophic culture period within all engineered tissues, with alginate and fibrin constructs accumulating significantly more calcium compared to chitosan constructs $(p<0.01)$, see Figure 1c. The switch from chondrogenic to hypertrophic culture conditions at week 5 did not result in significant changes in sGAG content within the engineered constructs by week 8 (Figure 1a). However, sGAG release to the media from alginate constructs increased dramatically during this period, with more modest releases observed in the chitosan and fibrin constructs (Figure 2).

Alginate constructs had a significantly higher wet weight at all time points (Figure 3a), and so when normalized to \%wet weight, sGAG and collagen accumulation was highest in chitosan constructs (Figures $3 \mathrm{~b}$ and $3 \mathrm{c}$ ), whereas calcium accumulation was highest in fibrin constructs (Figure 3d).

\subsubsection{Histology and immunohistochemistry}


Histology and immunohistochemistry performed at week 8 indicated that all engineered constructs supported robust chondrogenesis, with aldehyde fuschin/ alcian blue staining demonstrating the production of sGAG and immunohistochemical staining demonstrating the synthesis of collagen type II (Figure 4). Alizarin red staining demonstrated the deposition of a ring of calcium around the periphery of alginate and chitosan constructs, whereas fibrin constructs supported more homogenous calcium production throughout the engineered tissue.

\subsection{Endochondral bone formation following subcutaneous implantation of MSC-seeded alginate, chitosan and fibrin hydrogels}

\subsubsection{Histology and immunohistochemistry}

MSC-seeded alginate, chitosan, and fibrin hydrogels were cultured in chondrogenic conditions for a period of 5 weeks, followed by an additional week in hypertrophic culture conditions, prior to subcutaneous implantation in nude mice for 6 weeks. A single axially aligned channel $(\varnothing 2 \mathrm{~mm})$ was cored into these construct cylinders immediately before implantation to better mimic the geometry of the mid-section of a long bone and to provide an additional conduit for vaseularization. Pre-implantation, all constructs stained positive for

sGAG and collagen type II, but weakly for collagen type I (Figure 5). Alginate constructs also stained weakly for collagen type X pre-implantation, whereas chitosan and fibrin constructs stained more strongly for collagen type X. Post-implantation, a loss of chondrogenic phenotype was observed in alginate and fibrin constructs, as evidenced by a dramatic increase in the intensity of collagen type I and type $\mathrm{X}$ immunostaining and a decrease in sGAG staining. Chitosan appeared to better support the maintenance of a chondrogenic phenotype in vivo, as demonstrated by more intense staining for sGAG, and weaker staining for collagen type $\mathrm{X}$ post-implantation. It should be noted however, that a reduction in type II collagen deposition was also observed in chitosan hydrogels in vivo. 
H\&E staining was used to assess spatial bone tissue formation post-implantation (Figure 6). Alginate and fibrin constructs both supported bone formation at the top of the construct (Figure 6a,c). Central sections of fibrin constructs demonstrated the presence of a marrow component consisting of a mixture of hematopoietic foci and marrow adipose tissue, though less bone formation was observed at this depth (Figure 6f). Alginate constructs appeared to support greater bone formation in the central region of the engineered construct, with evidence of trabecular strut formation and bone marrow foci accompanied by blood vessel infiltration (Figure 6d). The formation of fibrovascular and bone marrow tissue within alginate and fibrin constructs appeared to correlate with the regions within these hydrogels undergoing dissolution/degradation. Chitosan hydrogels supported the development of a bony collar on the periphery of the construct, although there was no evidence of bone formation or vascularization within the body of the hydrogel at any depth (Figure 6e,f).

\subsubsection{Micro-computed tomography}

Prior to implantation, all constructs had begun to mineralize around their periphery (Figure 7a). Micro-computed tomography $(\mu \mathrm{CT})$ analysis of engineered tissues post-implantation revealed that, to different degrees, continued calcification occurred within all constructs in vivo (Figure 7b). In general, calcification appeared more confined to the periphery of chitosan constructs, but more diffuse with alginate. For all constructs, mineralization decreased with depth through the tissue. Macroscopic observation suggested that chitosan and fibrin constructs better retained their pre-implantation shape, with the cylindrical core still evident throughout the depth of the tissue, whereas in alginate constructs this core region was only partially retained with the overall shape and geometry of the construct becoming distorted (Figure 7c). This macroscopic assessment also suggested that alginate and fibrin constructs facilitated higher levels of vascularization. Alginate constructs appeared to support the greatest degree of mineralization, which was confirmed by $\mu \mathrm{CT}$ quantification, with bone 
volume being significantly higher in alginate constructs $(43.08 \pm 8.6 \% \mathrm{BV} / \mathrm{TV})$ as compared to chitosan $(\mathrm{p}=0.0073)$ and fibrin $(\mathrm{p}=0.04)$ constructs (Figure $7 \mathrm{~d})$. The local density of the newly formed bone in alginate constructs $\left(748.42 \pm 42.26 \mathrm{mg} \mathrm{HA} / \mathrm{cm}^{3}\right)$ was significantly $(\mathrm{p}=0.005)$ higher when compared to chitosan constructs (Figure 7e). The total bone density was also significantly higher in alginate constructs (Figure 7f).

\section{Discussion}

MSC based articular cartilage tissue engineering strategies require the identification of hydrogels that support the maintenance of a stable chondrogenic phenotype. In contrast, the scaling-up of engineered hypertrophic cartilaginous grafts to treat bone defects of a clinically relevant size requires the use of a suitable scaffolding material tailored to facilitate chondrogenesis and the transition from engineered hypertrophic cartilage into bone. The objective of this study was to compare the capacity of different naturally derived hydrogels (alginate, chitosan, and fibrin) to support the in vitro development of either articular or hypertrophic cartilaginous tissues using MSCs, as well as the capacity of such hydrogels to facilitate endochondral bone formation in vivo. In vitro, alginate and chitosan constructs accumulated the highest levels of sGAG, with chitosan constructs synthesising the highest levels of collagen. Alginate and fibrin constructs supported the greatest degree of calcium accumulation in vitro, though only fibrin constructs calcified homogenously. In vivo, both alginate and fibrin constructs facilitated vascularization and endochondral bone formation as well as the development of a bone marrow environment, with alginate constructs accumulating significantly more mineral and supporting greater bone formation in central regions of the engineered tissue. Chitosan hydrogels appeared to best maintain a stable 
chondrogenic phenotype, although some mineralization of the engineered tissue was still observed in vivo.

Understanding how cell-material interactions regulate stem cell fate is a key challenge in developing successful tissue engineering therapies. Cells encapsulated in alginate cannot directly adhere to the hydrogel and hence adopt a spherical morphology known to promote chondrogenesis, which coupled with the significant construct swelling and capacity of this hydrogel to retain synthesized matrix components (Fig. 2), may explain the large accumulation in sGAG during culture in chondrogenic conditions. Unlike alginate, fibrin permits cell mediated integrin binding [33] and a more spread MSC morphology [34], which in turn may support robust osteogenic [35] and/or endochondral differentiation. This may explain why in contrast to alginate and chitosan constructs, which calcified preferentially around their periphery upon culture in hypertrophic conditions, fibrin constructs facilitated a homogenous deposition of calcium in vitro while accumulating the highest levels of calcium when normalized by $\%$ wet weight. Previous studies have suggested that the development of a low oxygen micro-environment within core regions of MSC-seeded hydrogels will suppress hypertrophy and calcification in this region of the engineered tissue [31]. In the context of MSC seeded fibrin gels, it may be that the combination of a spread cell shape and such low oxygen conditions are supporting a sub-population of MSCs undergoing direct osteoblastic differentiation in response to the $\beta$-GP (an osteogenic inducer) within the hypertrophic medium, as previous studies have demonstrated enhanced calcium deposition by MSCs at an oxygen tension of $5 \%$ pO2 compared to $20 \%$ pO2 [30, 36]. Previous studies have also demonstrated that MSCs cultured in a chondrogenic medium containing $\beta$-GP accumulated more calcium in hypoxic conditions than in normoxic conditions when seeded onto an electrospun fibrous polymer scaffold [37], a scaffold which also promotes an elongated 
morphology in MSCs [38]. Further work is required to determine the role of cell shape and oxygen tension in regulating the endochondral phenoype of MSCs.

Chitosan constructs appeared to generate the most stable cartilage-like tissue over the 8 week in vitro culture period, as demonstrated by the highest levels of collagen and sGAG accumulation (as a \% of tissue wet weight) and lowest calcium accumulation. A number of previous studies have investigated the use of chitosan hydrogels for cartilage tissue engineering applications [39-43]. A linear polysaccharide, chitosan consists of $\beta(1 \rightarrow 4)$ linked D-glucosamine residues with a variable number of randomly located $\mathrm{N}$-acetylglucosamine groups and is structurally similar to a number of sGAGs and hyaluronic acids present in articular cartilage [44]. Furthermore, the cationic nature of chitosan facilitates the formation of ionic complexes with anionic polysaccharides such as sGAGs [45]. The chitosan hydrogel may therefore be supporting a favourable environment for the chondrogenesis of MSCs; firstly, by providing a structural framework containing cartilage specific biochemical cues, and secondly, by facilitating the development of a dense cartilaginous matrix through the entrapment of generated sGAGs, a mechanism which may be playing a further role in maintaining the chondrogenic phenotype. Interestingly, chitosan constructs experienced only a modest 2 fold increase in $\mathrm{sGAG}$ release to the culture media upon transition to hypertrophic conditions, as opposed to the dramatic 125 fold increase from alginate constructs during the same period. This polycation-polyanion structural relationship between the positively charged chitosan hydrogel and negatively charged sGAG may be the regulatory mechanism behind sGAG retention within the constructs.

When comparing the performance of various biopolymers, the purity of the different materials must be considered. The ultrapure alginate and chitosan polymers utilized in this study contained very low levels of endotoxins $(\leq 100 \mathrm{EU} / \mathrm{g})$, which may have had a beneficial effect on matrix accumulation within these hydrogels. The fibrinogen and thrombin utilized 
to form fibrin hydrogels had not been tested for endotoxins and therefore we are unable to confirm if they are of the same high purity as the alginate and chitosan hydrogels.

To assess the capacity of the alginate, chitosan and fibrin hydrogels to generate endochondral bone in vivo, engineered hypertrophic constructs were implanted subcutaneously into nude mice. Both alginate and fibrin constructs supported endochondral bone formation, vascularization, and the development of a hematopoietic marrow component. Interestingly both these hydrogels demonstrated levels of dissolution/degradation following implantation with vascularization and bone marrow formation apparently localised to the regions of scaffold degradation. Of the two hydrogels, alginate underwent the greater remodelling and facilitated the development of the highest levels endochondral bone formation. Interestingly, this occurred despite alginate constructs having demonstrated the lowest levels of hypertrophy pre-implantation (specifically these constructs stained weakest for type X collagen), with robust hypertrophic differentiation only evident following in vivo implantation. This was would suggest that relative levels of type $\mathrm{X}$ collagen production preimplantation are not necessarily predictive of the extent of endochondral bone formation in vivo. The more rapid degradation rate of the alginate in vivo is likely favoring vascularization and oxygen availability within this hydrogel, and subsequently driving hypertrophy [30, 46]. Tailoring the degradation characteristics of a hydrogel may therefore be of critical importance in promoting endochondral ossification of engineered grafts [47-50]. Alternatively, or perhaps in conjunction, inflammatory cytokines may be leveraged to direct more efficient resorption of a large cartilaginous template [51]. Hydrogels for endochondral applications may also benefit from the incorporation of channeled arrays, in order to provide additional conduits for vascularization [52].

Chitosan constructs did not undergo any degradation following in vivo implantation and only supported a collar of bone formation on the periphery of the hydrogel, nor was there 
any evidence of vascularization or marrow formation. The preservation of the chitosan hydrogel in vivo would seem to be playing a role in inhibiting bone formation and vascularization. While chitosan appeared to best support the chondrogenic phenotype of MSCs in vivo, with retention of the sGAG matrix again perhaps occurring through the polycation-polyanion mechanism described above, a sufficiently stable chondrogenic phenotype was not achieved as evident by a reduction in collagen type II and an increase in collagen types I and X production and matrix calcification. A previous study comparing the capacity of various hydrogels to support stable chondrogenesis of adipose derived stem cells in vivo reported suppression of calcification by Matrigel [26]. However, when the source of stem cells was changed from adipose tissue to bone marrow, as used in this study, Matrigel calcification was also reported. Furthermore, cartilaginous tissues engineered using stem cells isolated from different sources have been shown to be phenotypically different [31]. Therefore, MSC-based articular cartilage repair therapies would appear to depend greatly on the source from which the MSCs are isolated and the hydrogel in which they are encapsulated. Chitosan hydrogels, provided they're loaded with the appropriate stem cell source, may be an attractive material for the engineering of phenotypically stable and functional articular cartilage for use in orthotopic defects. Further studies are required to test this concept in appropriate models.

\section{Conclusions}

This work examined the capacity of different naturally derived hydrogels to support chondrogenesis and hypertrophy of MSCs in vitro and endochondral ossification in vivo. All hydrogels supported, to differing degrees, the development of mineralized cartilage in vitro, though only alginate and fibrin hydrogels facilitated endochondral bone formation in vivo, with alginate constructs accumulating significantly more mineral and supporting bone 
formation in central regions of the engineered tissue. Chitosan hydrogels better maintained the chondrogenic phenotype of MSCs, suggesting it to be a promising material for the engineering of articular cartilage. Future work will explore the capacity of alginate hydrogels to support endochondral bone formation in large bone defects, and furthermore, to form an anatomically shaped tissue engineered long bone as a paradigm for whole bone regeneration through endochondral ossification.

\section{Acknowledgements}

This work was supported by Science Foundation Ireland (SFI/08/Y15/B1336) and the European Research Council (StemRepair-Project No: 258463). 


\section{References}

[1] Koh CJ, Atala A. Tissue Engineering, Stem Cells, and Cloning: Opportunities for Regenerative Medicine. J Am Soc Nephrol 2004;15:1113-25.

[2] Langer R. Tissue Engineering. Mol Ther 2000;1:12-5.

[3] Meijer GJ, De Bruijn JD, Koole R, Van Blitterswijk CA. Cell-based bone tissue engineering. PLoS Medicine 2007;4:0260-4.

[4] Santos MI, Reis RL. Vascularization in bone tissue engineering: Physiology, current strategies, major hurdles and future challenges. Macromolecular Bioscience 2010;10:12-27.

[5] Lyons FG, Al-Munajjed AA, Kieran SM, Toner ME, Murphy CM, Duffy GP, O'Brien FJ. The healing of bony defects by cell-free collagen-based scaffolds compared to stem cell-seeded tissue engineered constructs. Biomaterials 2010;31:9232-43.

[6] Lenas P, Moos M, Luyten FP. Developmental engineering: A new paradigm for the design and manufacturing of cell-based products. Part I: From three-dimensional cell growth to biomimetics of in Vivo development. Tissue Engineering - Part B: Reviews 2009;15:381-94.

[7] Kronenberg HM. Developmental regulation of the growth plate. Nature 2003;423:332-6.

[8] Farrell $\mathrm{E}$, et al. In-vivo generation of bone via endochondral ossification by in-vitro chondrogenic priming of adult human and rat mesenchymal stem cells. BMC Musculoskelet Disord 2011;12.

[9] Farrell E, et al. Chondrogenic priming of human bone marrow stromal cells: A better route to bone repair? Tissue Eng Part C Methods 2009;15:285-95.

[10] Huang JI, Durbhakula MM, Angele P, Johnstone B, Yoo JU. Lunate arthroplasty with autologous mesenchymal stem cells in a rabbit model. J Bone Joint Surg 2006;88:744-52.

[11] Scotti C, et al. Recapitulation of endochondral bone formation using human adult mesenchymal stem cells as a paradigm for developmental engineering. Proc Natl Acad Sci U S A 2010;107:7251-6.

[12] Janicki P, Kasten P, Kleinschmidt K, Luginbuehl R, Richter W. Chondrogenic pre-induction of human mesenchymal stem cells on $\beta$-TCP: Enhanced bone quality by endochondral heterotopic bone formation. Acta Biomater 2010;6:3292-301.

[13] Scotti C, et al. Engineering of a functional bone organ through endochondral ossification. Proc Natl Acad Sci U S A 2013;110:3997-4002.

[14] Harada $\mathrm{N}$, et al. Bone regeneration in a massive rat femur defect through endochondral ossification achieved with chondrogenically differentiated MSCs in a degradable scaffold.

Biomaterials 2014;35:7800-10.

[15] van der Stok J, Koolen MK, Jahr H, Kops N, Waarsing JH, Weinans H, van der Jagt OP. Chondrogenically differentiated mesenchymal stromal cell pellets stimulate endochondral bone regeneration in critical-sized bone defects. Eur Cell Mater 2014;27:137-48; discussion 48.

[16] Riley SL, Dutt S, De La Torre R, Chen AC, Sah RL, Ratcliffe A. Formulation of PEG-based hydrogels affects tissue-engineered cartilage construct characteristics. Journal of materials science Materials in medicine 2001;12:983-90.

[17] Drury JL, Mooney DJ. Hydrogels for tissue engineering: Scaffold design variables and applications. Biomaterials 2003;24:4337-51.

[18] Erickson IE, Huang AH, Chung C, Li RT, Burdick JA, Mauck RL. Differential maturation and structure-function relationships in mesenchymal stem cell- and chondrocyte-seeded hydrogels. Tissue Eng Part A 2009;15:1041-52.

[19] Mauck RL, Yuan X, Tuan RS. Chondrogenic differentiation and functional maturation of bovine mesenchymal stem cells in long-term agarose culture. Osteoarthritis Cartilage 2006;14:179-89. [20] Sheehy EJ, Buckley CT, Kelly DJ. Chondrocytes and bone marrow-derived mesenchymal stem cells undergoing chondrogenesis in agarose hydrogels of solid and channelled architectures respond differentially to dynamic culture conditions. J Tissue Eng Regen Med 2011;5:747-58.

[21] Ma K, Titan AL, Stafford M, Zheng C, Levenston ME. Variations in chondrogenesis of human bone marrow-derived mesenchymal stem cells in fibrin/alginate blended hydrogels. Acta Biomater 2012;8:3754-64. 
[22] Erickson IE, Kestle SR, Zellars KH, Farrell MJ, Kim M, Burdick JA, Mauck RL. High mesenchymal stem cell seeding densities in hyaluronic acid hydrogels produce engineered cartilage with native tissue properties. Acta Biomater 2012;8:3027-34.

[23] Awad HA, Wickham MQ, Leddy HA, Gimble JM, Guilak F. Chondrogenic differentiation of adipose-derived adult stem cells in agarose, alginate, and gelatin scaffolds. Biomaterials

2004;25:3211-22.

[24] Bosnakovski D, Mizuno M, Kim G, Takagi S, Okumura M, Fujinaga T. Chondrogenic differentiation of bovine bone marrow mesenchymal stem cells (MSCs) in different hydrogels: influence of collagen type II extracellular matrix on MSC chondrogenesis. Biotechnol Bioeng 2006;93:1152-63.

[25] Coleman RM, Case ND, Guldberg RE. Hydrogel effects on bone marrow stromal cell response to chondrogenic growth factors. Biomaterials 2007;28:2077-86.

[26] Kim IL, Mauck RL, Burdick JA. Hydrogel design for cartilage tissue engineering: a case study with hyaluronic acid. Biomaterials 2011;32:8771-82.

[27] Dickhut A, Gottwald E, Steck E, Heisel C, Richter W. Chondrogenesis of mesenchymal stem cells in gel-like biomaterials in vitro and in vivo. Frontiers in bioscience : a journal and virtual library 2008;13:4517-28.

[28] de Vries-van Melle ML, et al. Chondrogenic differentiation of human bone marrow-derived mesenchymal stem cells in a simulated osteochondral environment is hydrogel dependent. Eur Cell Mater 2014;27:112-23; discussion 23.

[29] Pleumeekers MM, Nimeskern L, Koevoet WL, Kops N, Poublon RM, Stok KS, van Osch GJ. The in vitro and in vivo capacity of culture-expanded human cells from several sources encapsulated in alginate to form cartilage. Eur Cell Mater 2014;27:264-80; discussion 78-80.

[30] Sheehy EJ, Buckley CT, Kelly DJ. Oxygen tension regulates the osteogenic, chondrogenic and endochondral phenotype of bone marrow derived mesenchymal stem cells. Biochem Biophys Res Commun 2012;417:305-10.

[31] Vinardell T, Sheehy EJ, Buckley CT, Kelly DJ. A comparison of the functionality and in vivo phenotypic stability of cartilaginous tissues engineered from different stem cells sources. Tissue Eng Part A 2012;18:1161-70.

[32] Sheehy EJ, Vinardell T, Buckley CT, Kelly DJ. Engineering osteochondral constructs through spatial regulation of endochondral ossification. Acta Biomater 2013;9:5484-92.

[33] Cheresh DA, Berliner SA, Vicente V, Ruggeri ZM. Recognition of distinct adhesive sites on fibrinogen by related integrins on platelets and endothelial cells. Cell 1989;58:945-53.

[34] Thorpe SD, Buckley CT, Steward AJ, Kelly DJ. European Society of Biomechanics S.M. Perren Award 2012: The external mechanical environment can override the influence of local substrate in determining stem cell fate. J Biomech 2012.

[35] McBeath R, Pirone DM, Nelson CM, Bhadriraju K, Chen CS. Cell shape, cytoskeletal tension, and RhoA regulate stem cell lineage commitment. Dev Cell 2004;6:483-95.

[36] Lennon DP, Edmison JM, Caplan Al. Cultivation of rat marrow-derived mesenchymal stem cells in reduced oxygen tension: Effects on in vitro and in vivo osteochondrogenesis. J Cell Physiol 2001;187:345-55.

[37] Meretoja VV, Dahlin RL, Wright S, Kasper FK, Mikos AG. The effect of hypoxia on the chondrogenic differentiation of co-cultured articular chondrocytes and mesenchymal stem cells in scaffolds. Biomaterials 2013;34:4266-73.

[38] Yang Y, Wimpenny I, Ahearne M. Portable nanofiber meshes dictate cell orientation throughout three-dimensional hydrogels. Nanomedicine : nanotechnology, biology, and medicine 2011;7:131-6. [39] Hoemann CD, Sun J, Legare A, McKee MD, Buschmann MD. Tissue engineering of cartilage using an injectable and adhesive chitosan-based cell-delivery vehicle. Osteoarthritis Cartilage 2005;13:31829. 
[40] Roughley P, Hoemann C, DesRosiers E, Mwale F, Antoniou J, Alini M. The potential of chitosanbased gels containing intervertebral disc cells for nucleus pulposus supplementation. Biomaterials 2006;27:388-96.

[41] Richardson SM, Hughes N, Hunt JA, Freemont AJ, Hoyland JA. Human mesenchymal stem cell differentiation to NP-like cells in chitosan-glycerophosphate hydrogels. Biomaterials 2008;29:85-93. [42] Park H, Choi B, Hu J, Lee M. Injectable chitosan hyaluronic acid hydrogels for cartilage tissue engineering. Acta Biomater 2013;9:4779-86.

[43] Hao T, et al. The support of matrix accumulation and the promotion of sheep articular cartilage defects repair in vivo by chitosan hydrogels. Osteoarthritis Cartilage 2010;18:257-65.

[44] Suh JK, Matthew HW. Application of chitosan-based polysaccharide biomaterials in cartilage tissue engineering: a review. Biomaterials 2000;21:2589-98.

[45] Wen Y, Grøndahl L, Gallego MR, Jorgensen L, Møller EH, Nielsen HM. Delivery of dermatan sulfate from polyelectrolyte complex-containing alginate composite microspheres for tissue regeneration. Biomacromolecules 2012;13:905-17.

[46] Gawlitta D, Van Rijen MHP, Schrijver EJM, Alblas J, Dhert WJA. Hypoxia impedes hypertrophic chondrogenesis of human multipotent stromal cells. Tissue Eng Part A 2012;18:1957-66.

[47] Simmons CA, Alsberg E, Hsiong S, Kim WJ, Mooney DJ. Dual growth factor delivery and controlled scaffold degradation enhance in vivo bone formation by transplanted bone marrow stromal cells. Bone 2004;35:562-9.

[48] Alsberg E, Kong HJ, Hirano Y, Smith MK, Albeiruti A, Mooney DJ. Regulating bone formation via controlled scaffold degradation. Journal of Dental Research 2003;82:903-8.

[49] Jeon O, Bouhadir KH, Mansour JM, Alsberg E. Photocrosslinked alginate hydrogels with tunable biodegradation rates and mechanical properties. Biomaterials 2009;30:2724-34.

[50] Jeon O, Powell C, Solorio LD, Krebs MD, Alsberg E. Affinity-based growth factor delivery using biodegradable, photocrosslinked heparin-alginate hydrogels. Journal of controlled release : official journal of the Controlled Release Society 2011;154:258-66.

[51] Mumme $M$, et al. Interleukin-1 $\beta$ modulates endochondral ossification by human adult bone marrow stromal cells. European Cells and Materials 2012;24:224-36.

[52] Sheehy EJ, Vinardell T, Toner ME, Buckley CT, Kelly DJ. Altering the Architecture of Tissue Engineered Hypertrophic Cartilaginous Grafts Facilitates Vascularisation and Accelerates Mineralisation. PLoS ONE 2014;9. 


\section{Figure legends}

Figure 1. Phase 1. Biochemical analysis of alginate, chitosan and fibrin constructs at week 5 and week 8 of in vitro culture. (a) sGAG, (b) collagen and (c) calcium accumulation within constructs. Significance: $\mathrm{p}<0.05$, a vs. chitosan at same time point, $\mathrm{b}$ vs. fibrin at same time point, c vs. corresponding group at week 5. 3-4 constructs were analyzed biochemically at each time point.

Figure 2. Phase 1. sGAG content in the medium of alginate, chitosan, and fibrin constructs. Measurements were taken at week 4 and week 6 to capture the change in sGAG release kinetics upon transfer from chondrogenic to hypertrophic culture conditions. Significance: $p$ $<0.05$, a vs. chitosan constructs, b vs. fibrin constructs, c vs. corresponding group at week 4. 4 samples analyzed at each time point.

Figure 3. Phase 1. Biochemical content of alginate, chitosan and fibrin constructs at week 5 and week 8 of in vitro culture normalized to \% wet weight (\%ww). (a) Mass of the constructs (mg). (b) sGAG, (c) collagen and (d) calcium accumulation of the constructs normalized to \% wet weight (\%ww). Significance: $\mathrm{p}<0.05$, a vs. chitosan at same time point, b vs. fibrin at same time point, c vs. corresponding group at week $5, \mathrm{~d}$ vs corresponding group at day 0. 3-4 constructs were analyzed biochemically at each time point.

Figure 4. Phase 1. Histological and immunohistochemical analysis of alginate, chitosan and fibrin constructs at week 8 of in vitro culture. Constructs were stained for sGAG (aldehyde fuschin/ alcian blue), collagen type II, and calcium (alizarin red). Scale bar is $250 \mu \mathrm{m}$.

Figure 5. Phase 2. Histological and immunohistochemical analysis of alginate, chitosan and fibrin constructs at the end of the 6 week in vitro culture period (pre-implantation) and after the 6 week in vivo period (post-implantation). Constructs were stained for collagen type I, collagen type II, collagen type X and sGAG (aldehyde fuschin/ alcian blue). Scale bars are $500 \mu \mathrm{m}$.

Figure 6. Phase 2. H\&E staining of alginate, chitosan and fibrin constructs post-implantation. Staining was performed on slices taken from two depths, the top and the center, of each construct. (a-c) Top slices. (d-f) Center slices. (a,d) alginate, (b,e) chitosan, and (c,f) fibrin constructs. Arrows indicate blood vessel structures. 'at' indicates marrow adipose tissue. Main image scale bars are $250 \mu \mathrm{m}$. Inset scale bars are $50 \mu \mathrm{m}$. Note: the intense pink staining 
in chitosan constructs (images (b) and (e)) is as a result of the high eosinophilicity of the chitosan material.

Figure 7. Phase 2. Calcification of alginate, chitosan and fibrin constructs pre-implantation and post-implantation. (a) Alizarin red staining of alginate, chitosan and fibrin constructs preimplantation. Scale bar is $500 \mu \mathrm{m}$. (b) $\mu \mathrm{CT}$ imaging of alginate (left column), chitosan (center column) and fibrin (right column) constructs post-implantation. Sections, corresponding to a thickness of $96 \mu \mathrm{m}$, were analyzed at a depth of $25 \%$ from the top of the construct (quarter section) and at a depth of 50\% from the top of the construct (center section). Scale bar is $1 \mathrm{~mm}$. (c) Macroscopic image of alginate (left), chitosan (center) and fibrin (right) constructs post-implantation. Scale bar is $3 \mathrm{~mm}$. (d) \% Bone volume per total volume (BV/TV), (e) local bone density and (f) total bone density of alginate, chitosan and fibrin constructs post-implantation. Significance: $p<0.05$, a vs. chitosan, $b$ vs. fibrin. 4 constructs were analyzed per group by $\mu \mathrm{CT}$. HA-Hydroxyapatite. 
a



b

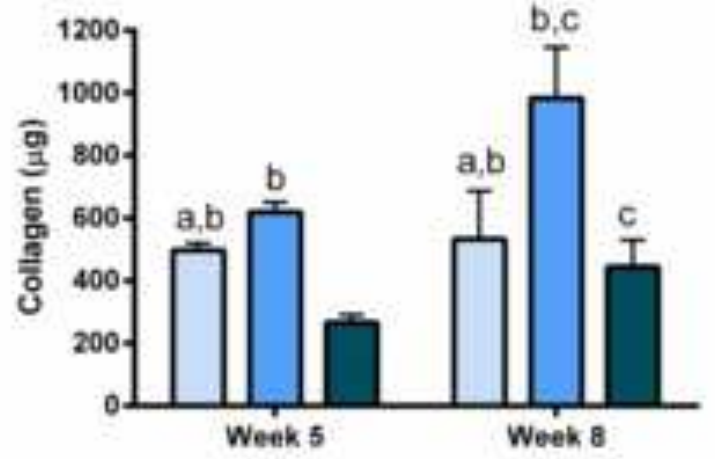

c

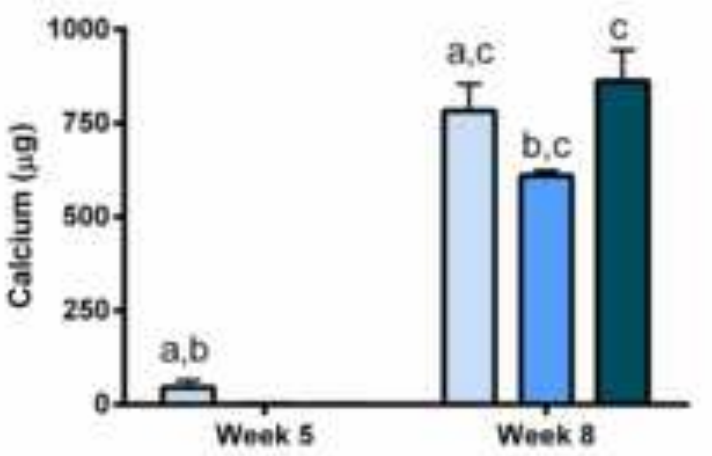




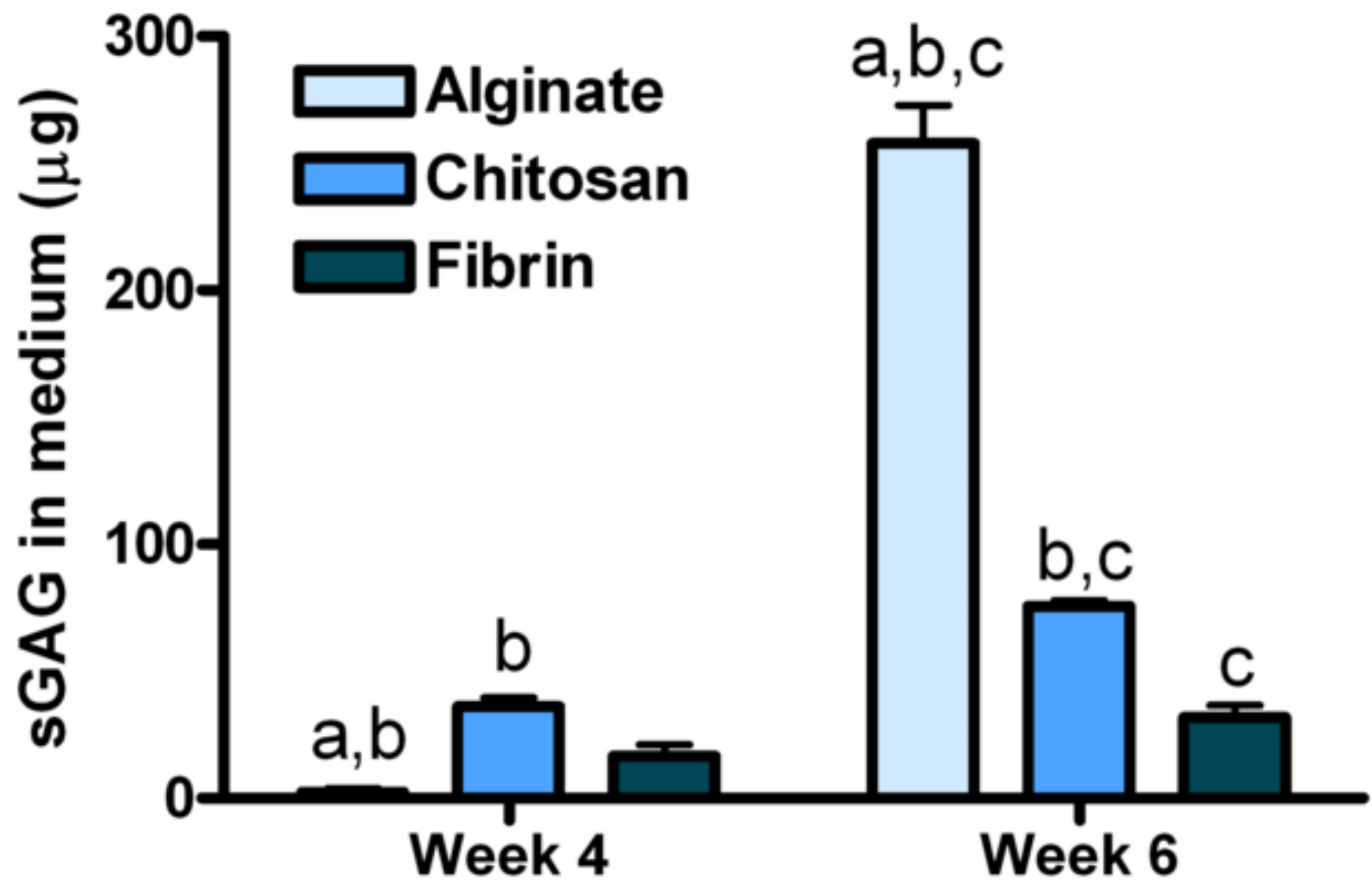



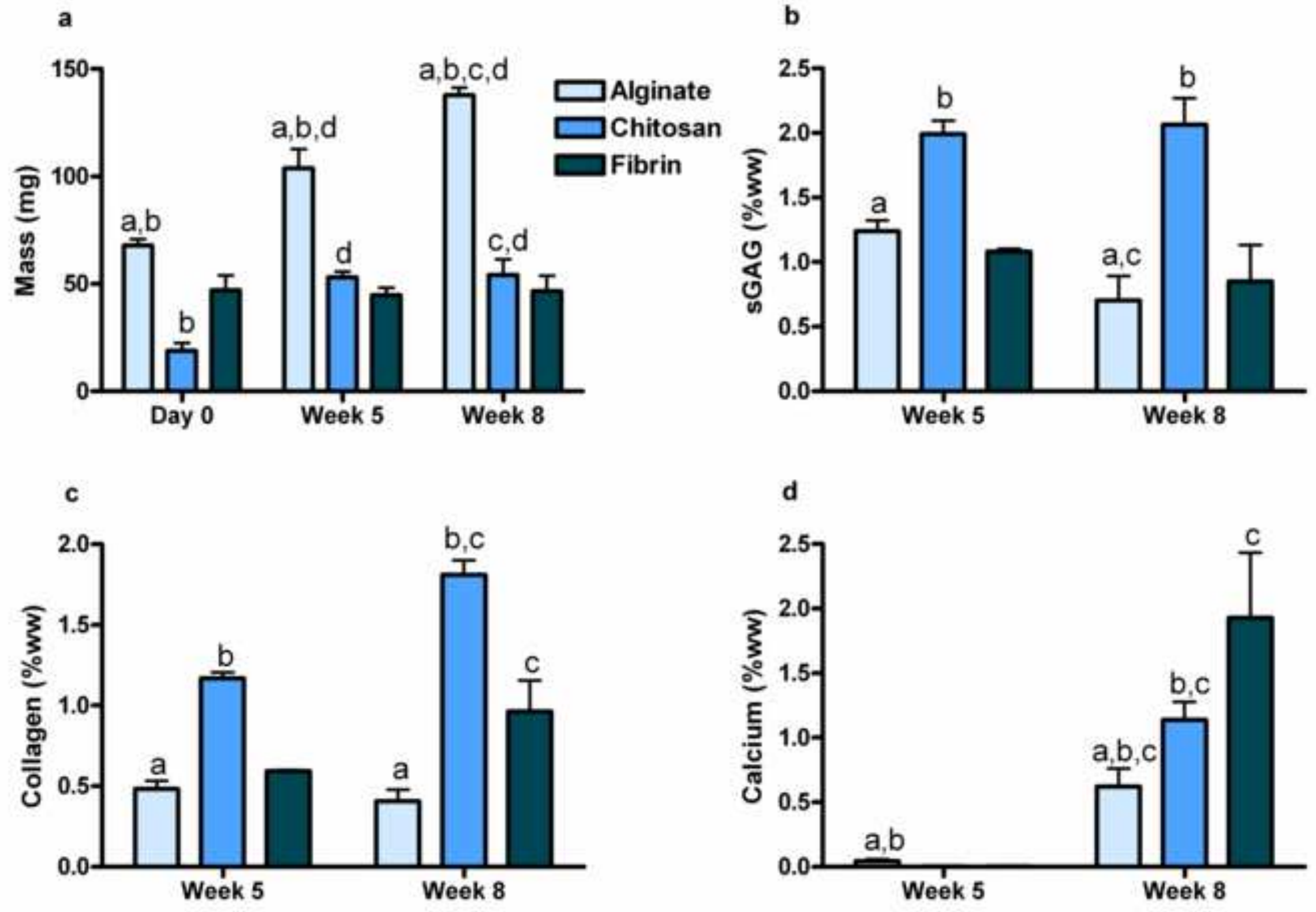
Click here to download high resolution image
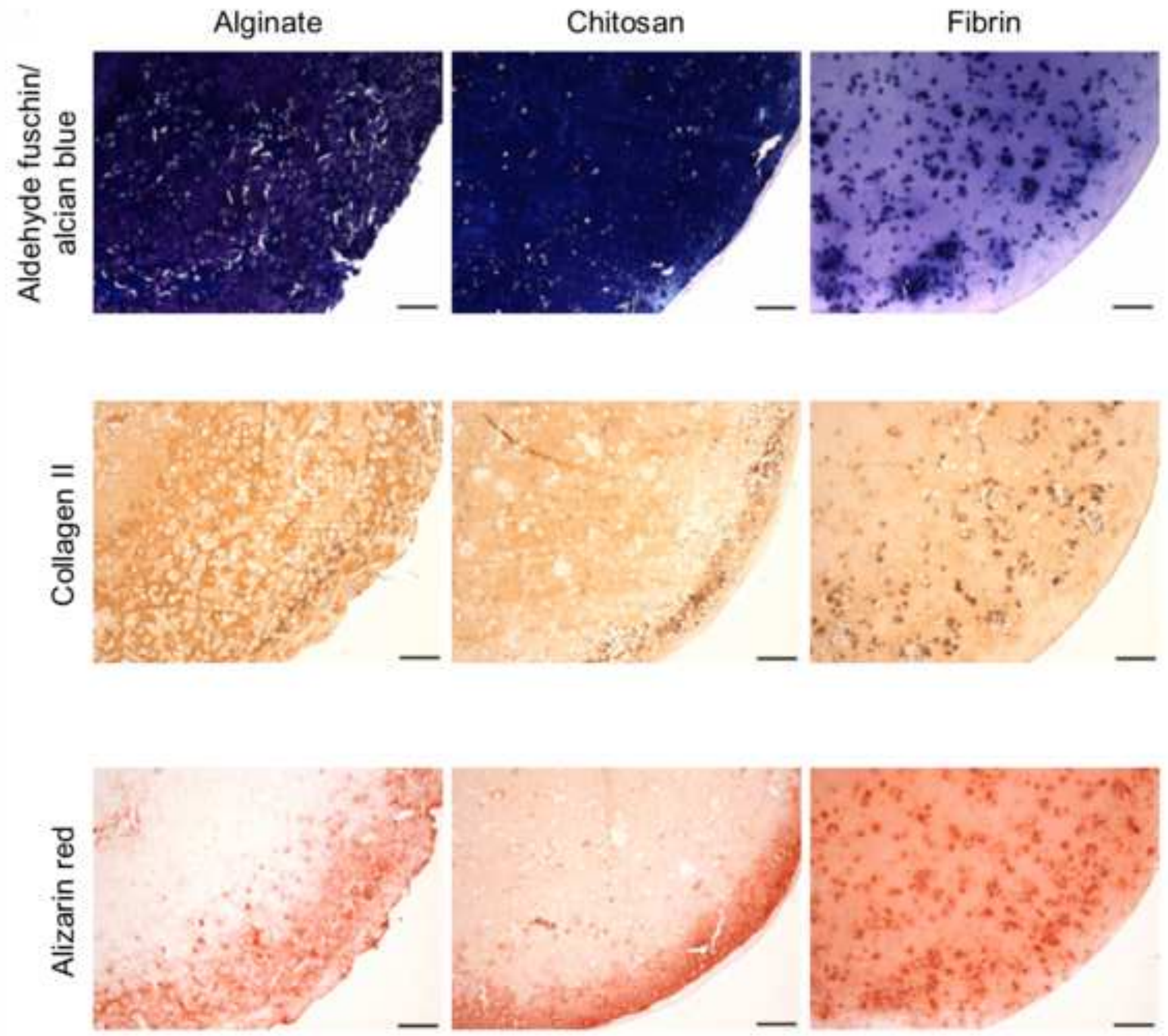
Figure 5
Click here to download high resolution image

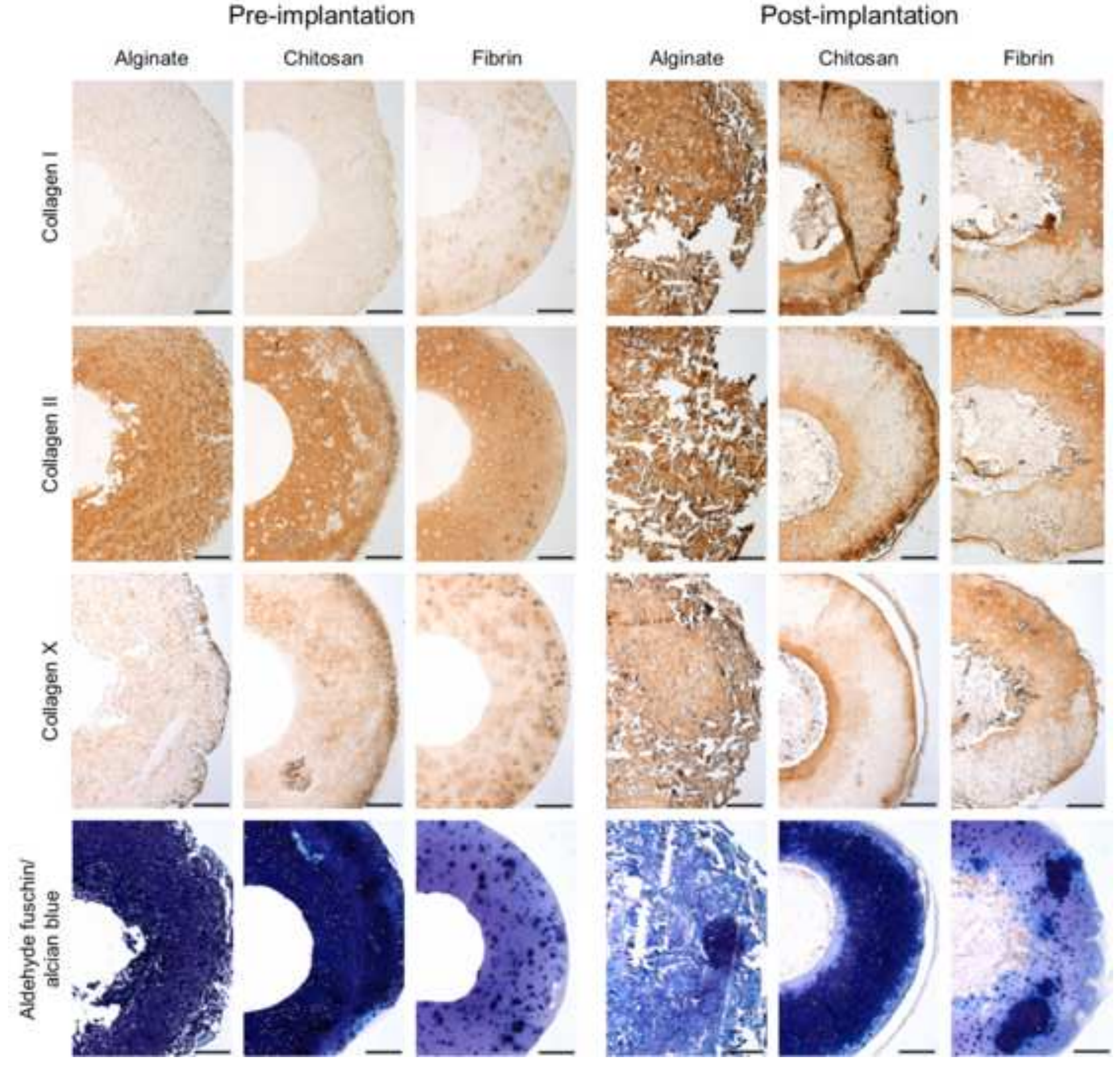


Click here to download high resolution image
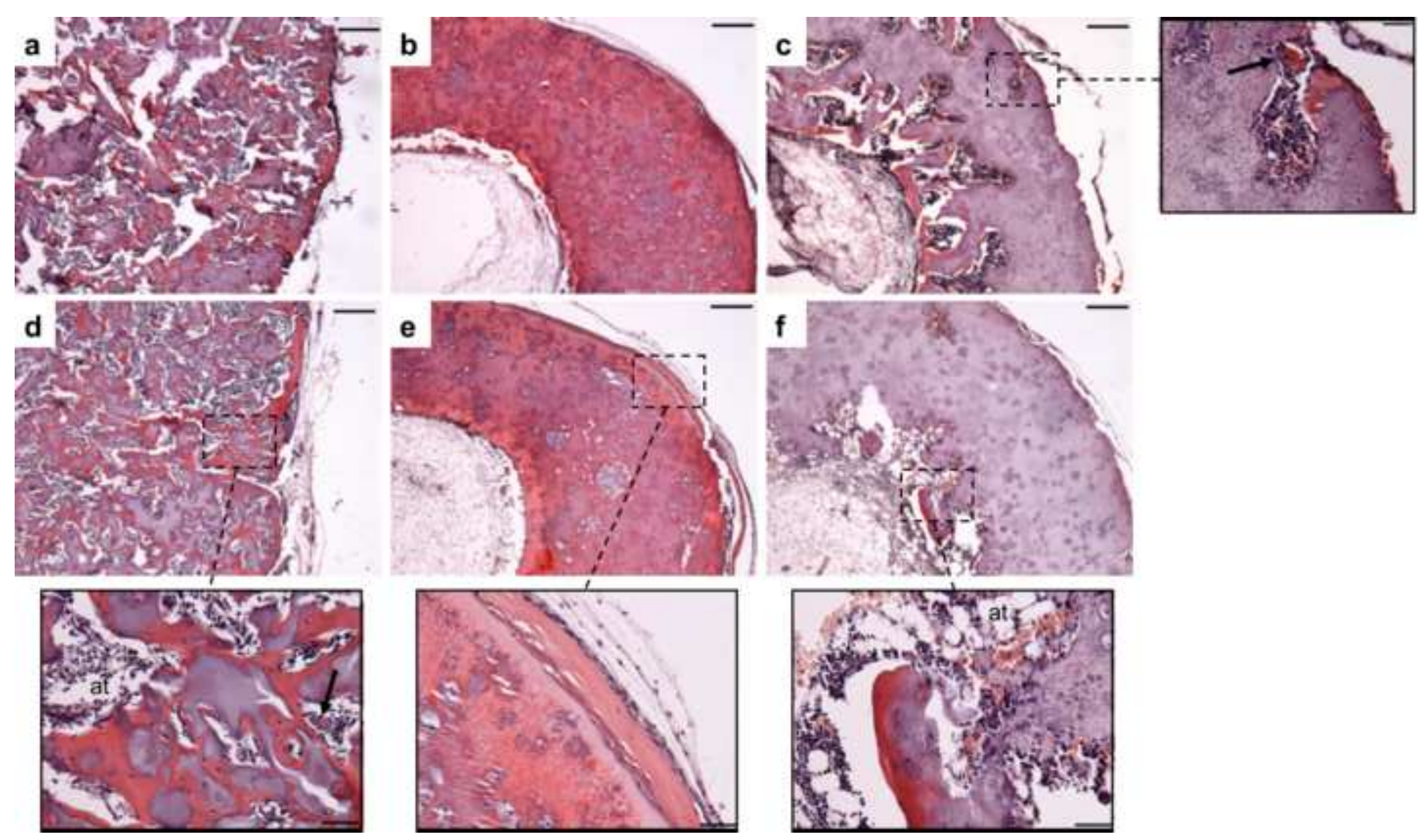
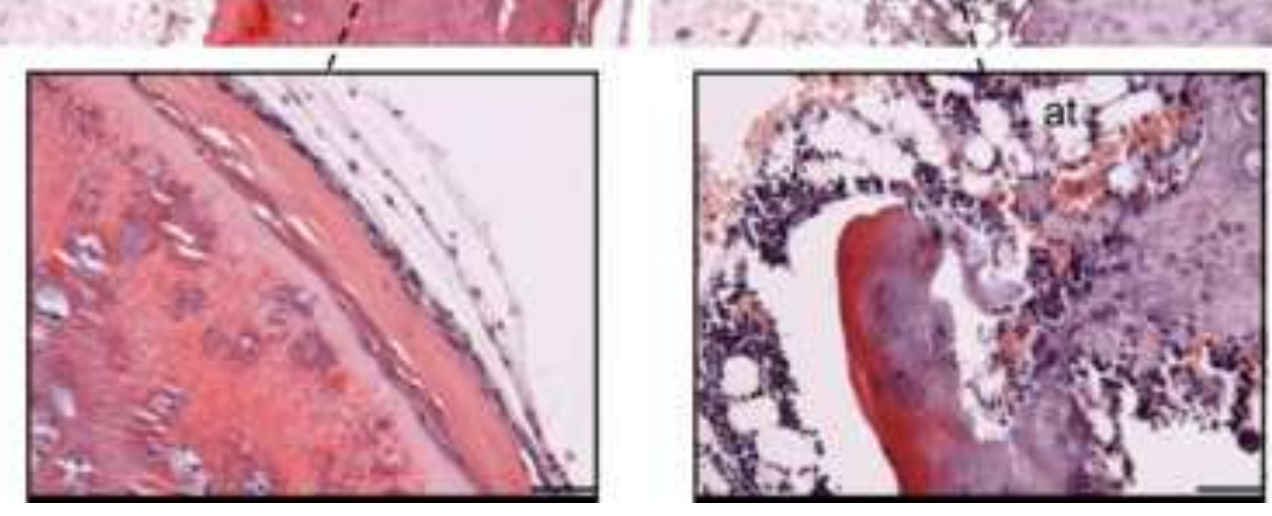

e

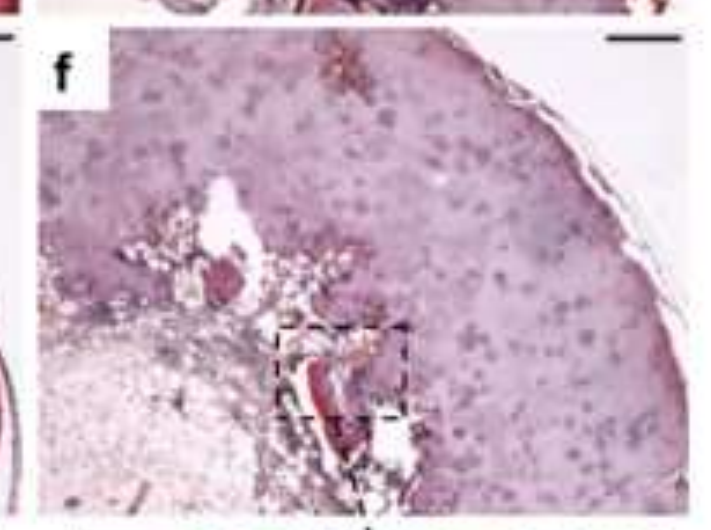


Click here to download high resolution image
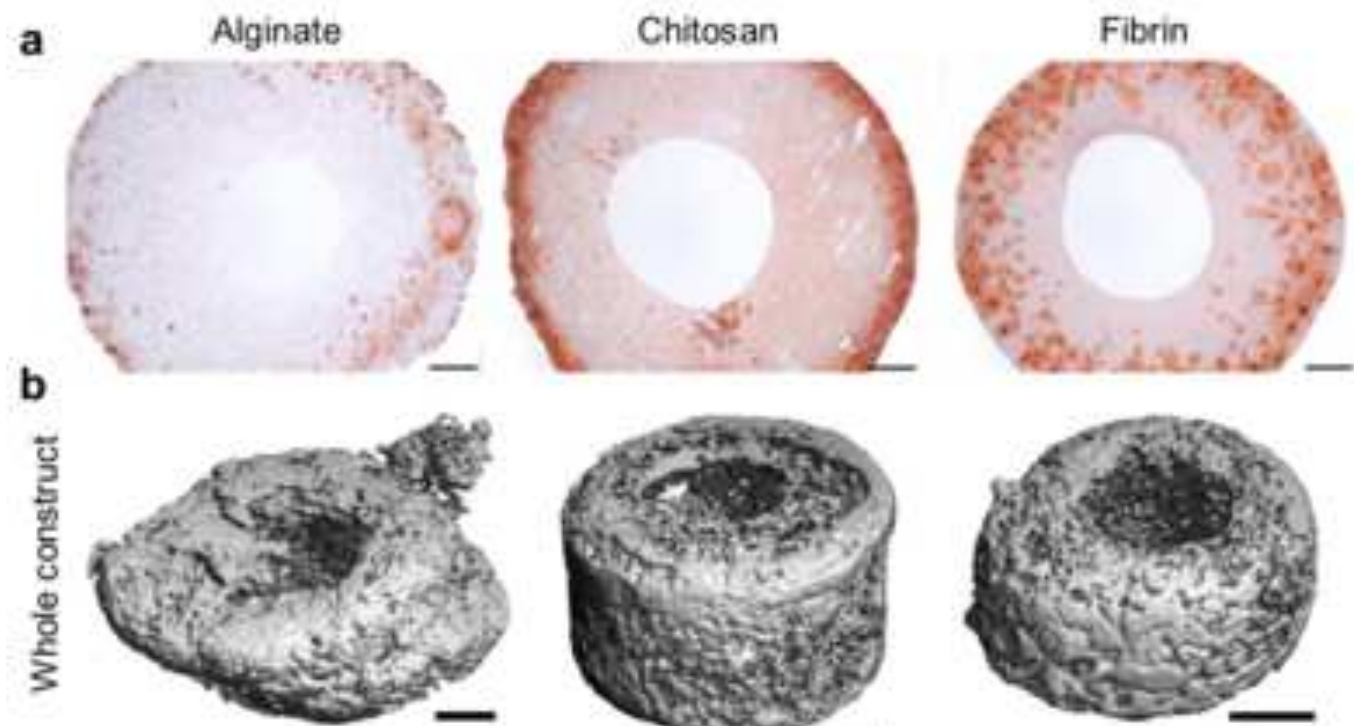

d
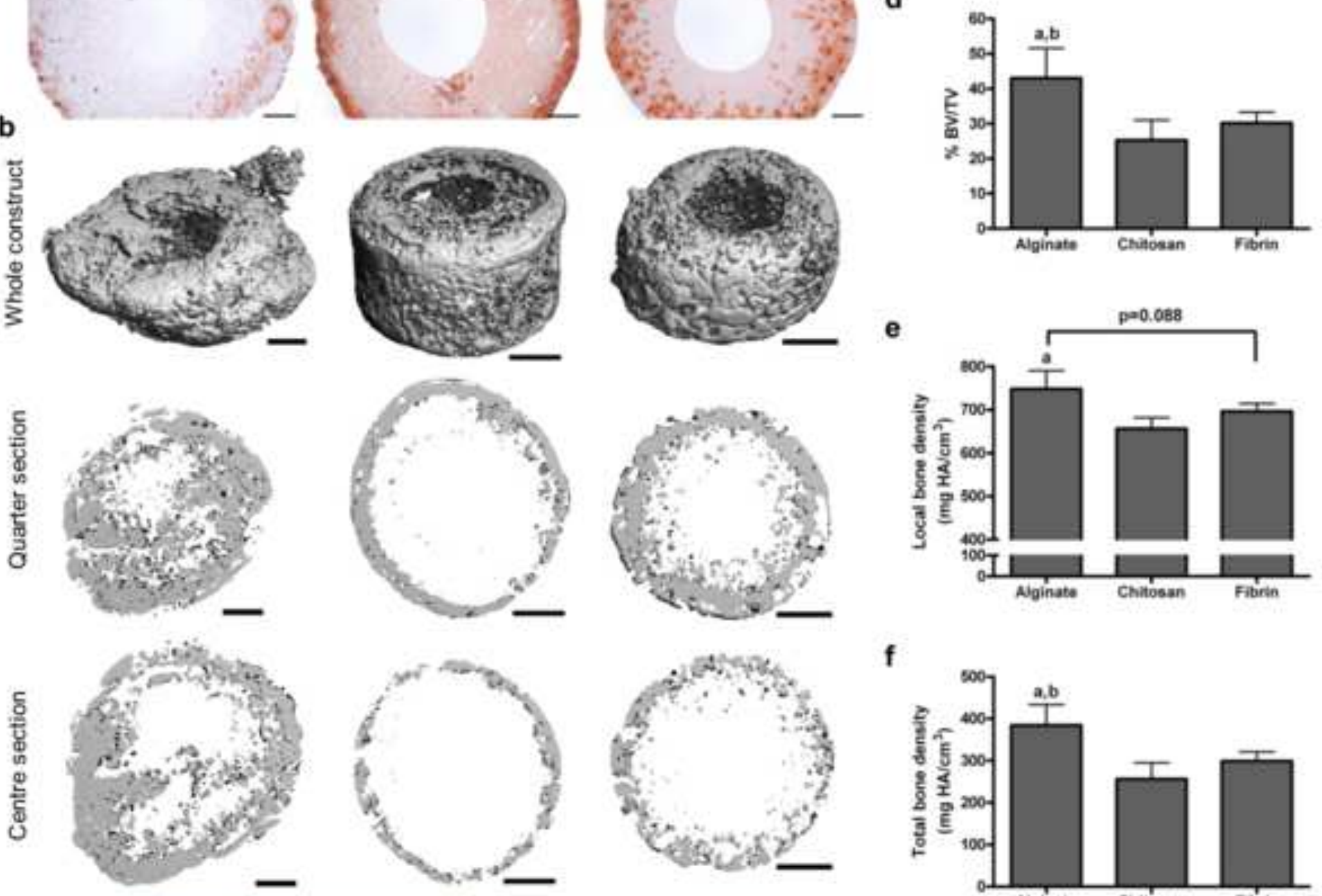

c
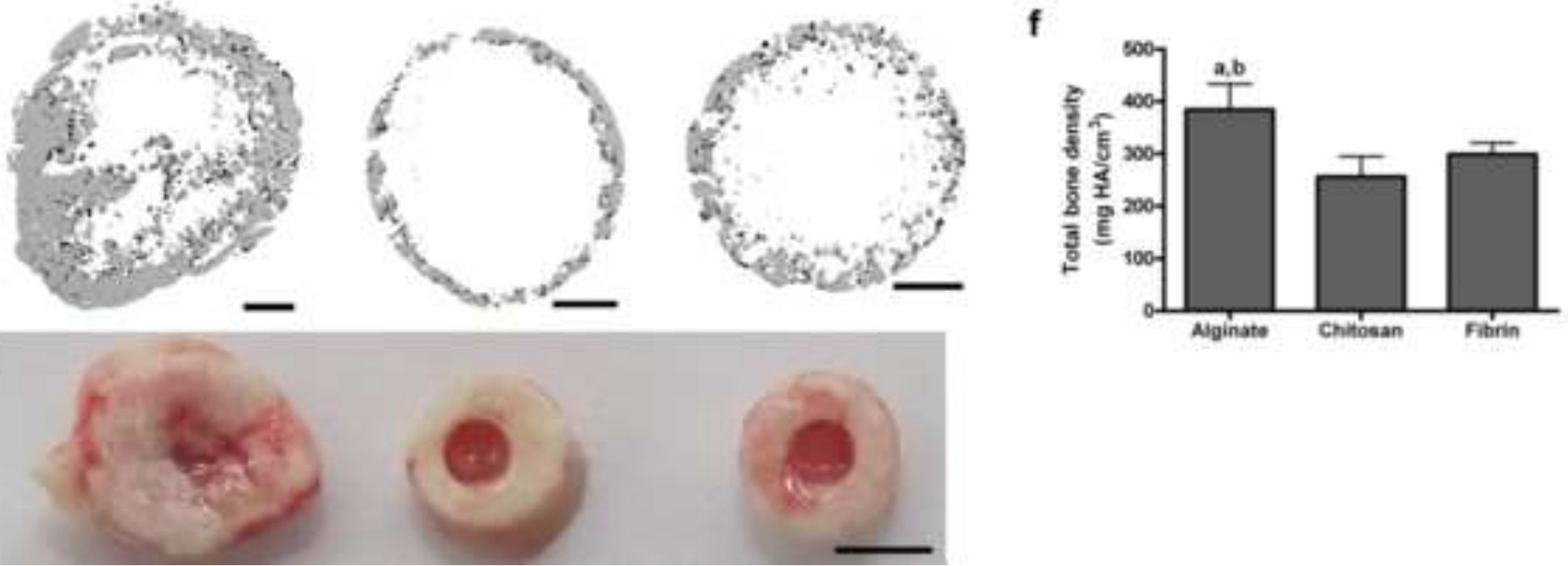
- MSC
Cartilage

Bone (1)

$\sqrt{2}+x^{2}$

Alginate
Fibrin

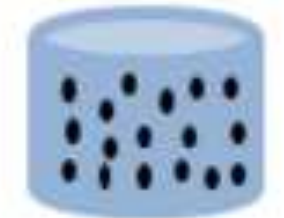

Chitosan
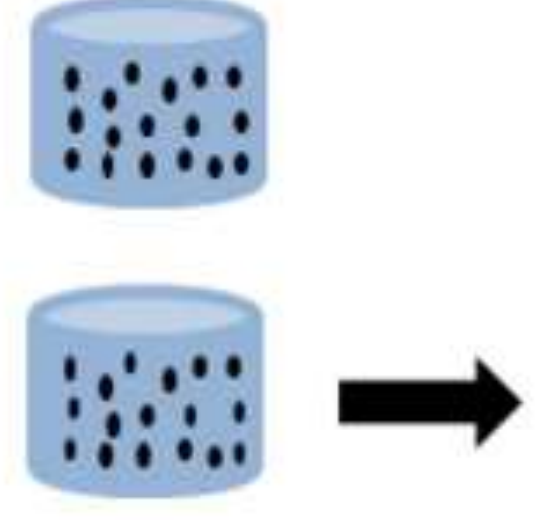

$$
10,000
$$

In vivo

$\because \because \because 6$

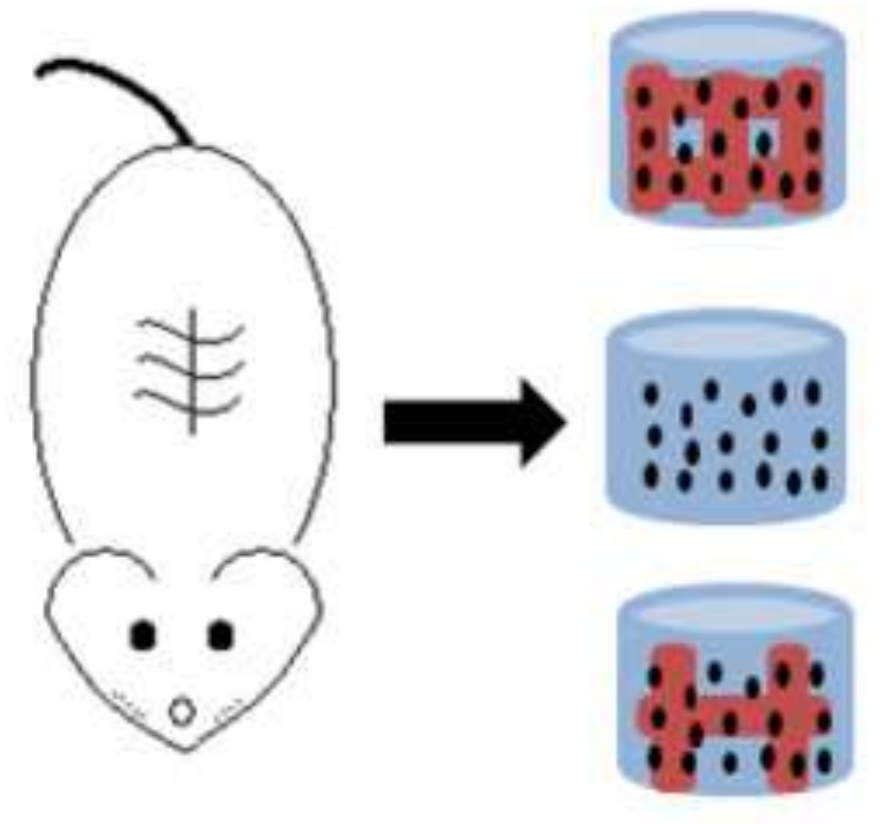

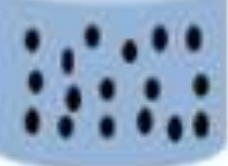

\section{Hydrogels In vitro}

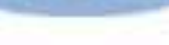

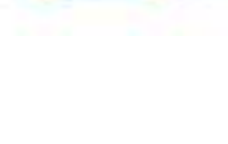


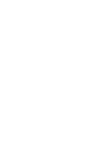

$\circ$

